\section{Kinetic Model for Nanocrystalline Anatase to Rutile Polymorphic Transformation}

\author{
R. Shakibania \\ Islamic Azad University, North Tehran Branch, \\ Department of Chemical Engineering, No. 79, Qobadian St., \\ Valiasr Ave., Postal code 1969633651, Tehran, Iran
}

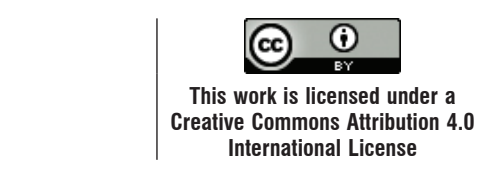

doi: 10.15255/CABEQ.2017.1094

Original scientific paper Received: February 13, 2017 Accepted: July 28, 2017

In this paper, kinetic models are presented for phase transformation from anatase to rutile in nanocrystalline samples at different temperature ranges. The models, in which the nucleation and growth are considered together, are able to predict the polymorphic transformation behavior of titania with better accuracy. In addition to researchers' assumption that phase transformation of nanocrystalline anatase to rutile at lower temperatures occurs only with interface nucleation, the results reveal that the surface nucleation can also have a significant role in the kinetics of phase transformation in conditions of prolonged heating. In comparison to other published models, the advantage of these models is that no experimental data regarding the size of particles is required to study the kinetics of phase transformation of $\mathrm{TiO}_{2}$ nanoparticles.

Key words:

anatase, kinetic model, rutile, titania

\section{Introduction}

Titania $\left(\mathrm{TiO}_{2}\right)$ occurs in at least seven different polymorphic forms ${ }^{1}$. Anatase, rutile, and brookite are the most common polymorphous of titania. Titania nanoparticles are employed in a wide range of applications, such as photocatalysis, pigments, ceramics, cosmetics, gas sensors, and dye-sensitized solar cells. The material properties of $\mathrm{TiO}_{2}$ nanoparticles are a function of the crystal structure, nanoparticle size, and morphology. For example, anatase crystals with regular crystal surfaces have a higher photocatalytic activity than those with irregular crystal surface ${ }^{2}$. Furthermore, the photocatalytic activity of nanocrystalline anatase is greater than that of rutile ${ }^{2}$, where the activity of nanocrystalline rutile increases with decrease in particle size ${ }^{2,3}$. Finally, the photocatalytic activity of amorphous titania is negligible ${ }^{4,5}$. On the other hand, using $\mathrm{TiCl}_{4}$, Zou et $a l^{6}$ have synthesized an amorphous $\mathrm{TiO}_{2}$ sol which demonstrated a higher photocatalytic activity for the photodegradation of methylene blue, in comparison with anatase sol.

Understanding the mechanism of the phase transformation of titania is fundamental to the control of the microstructure and, thus, its properties. The transformation between polymorphs involves kinetics and thermodynamics of process. Different polymorphs have different stability due to surface energy effects, and the growth of nanoparticles

"Corresponding author: E-mail address: r.shakibania@gmail.com; Tel: +98 9171408115 changes the surface energy and can thus profoundly affect the rate and mechanism of nanoparticle transport $^{7,8}$.

At standard conditions and macroscopic sizes, rutile is the most stable phase of titania thermodynamically, and upon heating, other phases are transformed to rutile ${ }^{9,10}$. Anatase-to-rutile is an irreversible transformation and there is no equilibrium transformation temperature, and that was observed at temperatures between 400 and $1200{ }^{\circ} \mathrm{C}$, depending on particle size, method of synthesis, impurity content, and the atmosphere ${ }^{9-11}$. It is observed that the transformation from anatase to rutile is initiated only when the particle size exceeds a certain size $(\sim 16-14 \mathrm{~nm})$, which is attributed to the reversal of the two-phase stability in this particle size, which is also confirmed by thermodynamic analysis $^{13,14}$.

The kinetics of the polymorphic transformation in titania from anatase to rutile has been studied intensively using anatase samples with different size at various temperatures ${ }^{9-11,14,15-27}$. Genari and Pasquevich $^{10}$, and Shanon and Pask ${ }^{11}$, stated that the solid-phase transformation is a process of nucleation and growth, and they used conventional models for transformation kinetic interpretation from anatase (micrometer size) to rutile. It has been demonstrated that conventional models (including standard first-order reaction, standard second-order reaction, contracting spherical interface model, model of random nucleation and rapid growth, model of nucleation and growth of overlapping nu- 
clei, model of one-dimensional, linear, branching nuclei and a constant growth, and Johnson-MehlAvrami-Kolmogorov (JMAK) equation) are not applicable in describing the kinetics of the phase transformation of nanocrystalline anatase ${ }^{12,28}$. Zhang and Banfield ${ }^{27,28}$, proposed kinetic models for $\mathrm{TiO}_{2}$ polymorphic transformation from nanocrystalline anatase to rutile, where their models incorporate nucleation mechanisms alongside experimental data of the size of anatase nanoparticles.

In this paper, we propose new kinetic models to describe published experimental data for the anatase to rutile phase transformation in nanocrystalline samples. The results reveal that kinetic models presented in this paper are able to predict the polymorphic transformation behavior of titania with better accuracy. The results also show that in some cases, the transformation kinetics can be well described with a different interpretation than the previous interpretations.

\section{Kinetic model}

The fraction of transformation, $\alpha$, for a dimorph phase transformation is defined ${ }^{28}$ as:

$$
\begin{aligned}
\alpha & =\frac{\frac{4}{3} \pi\left(\frac{D_{0}}{2}\right)^{3} \cdot N_{0} \cdot \rho-\frac{4}{3} \pi\left(\frac{D_{1}}{2}\right)^{3} \cdot N_{1} \cdot \rho}{\frac{4}{3} \pi\left(\frac{D_{0}}{2}\right)^{3} \cdot N_{0} \cdot \rho}= \\
& =1-\left(\frac{D_{1}}{D_{0}}\right)^{3} \cdot\left(\frac{N_{1}}{N_{0}}\right)
\end{aligned}
$$

where $D, N$ and $\rho$ represent the particle size, number of particles, and density of initial phase, respectively. Index 0 and 1 indicate, respectively, quantities at the initial reaction time $(t=0)$ and their values at any time $t$. According to Eq. (1), it can be written as:

$\alpha_{1 \rightarrow 2}=1-\left\{(\text { Increase in particle size of phase } 1)^{3}\right.$.

- (Decrease in particles number of phase 1$)\}$.

The number of particles of initial phase can be reduced, by interface nucleation (IN) and/or combined interface and surface nucleation $(\mathrm{IN}+\mathrm{SN})$, with time $e^{27,28}$ (Fig. 1):

$$
\begin{aligned}
& -\frac{\mathrm{d} N_{1}}{\mathrm{~d} t}=k_{1} N_{1}^{2} . \quad \text { (Decrease in particles } \\
& \text { number with } \mathrm{IN} \text { ) } \\
& -\frac{\mathrm{d} N_{1}}{\mathrm{~d} t}=k_{1} N_{1}^{2}+k_{2} N_{1} \cdot \begin{array}{l}
\text { (Decrease in particles } \\
\text { number with IN+SN) }
\end{array}
\end{aligned}
$$

where $k_{1}$ and $k_{2}$ represent the kinetic constants for the interface nucleation and the surface nucleation, respectively. These constants are a function of tem-

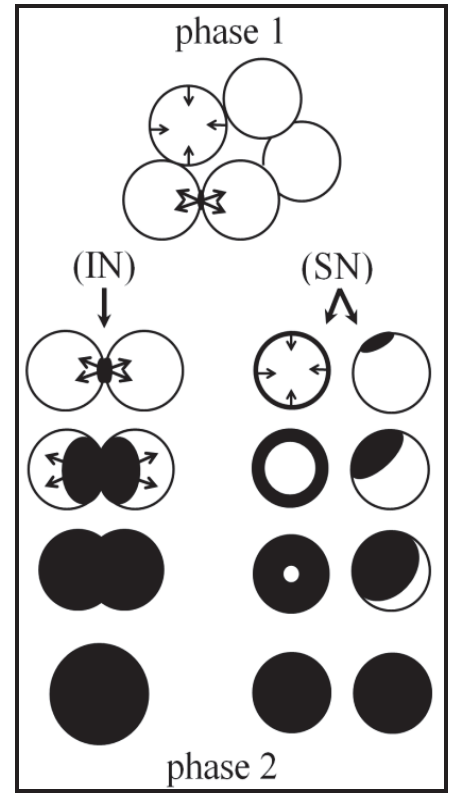

Fig. 1 - Diagram showing nucleation models in the solidphase transformation

perature and sample characteristics. Integrating Eqs. (3) and (4) from time $=0$ (when $N_{1}=N_{0}$ ) to time $t$, we obtain:

$$
\begin{aligned}
& \frac{N_{1}}{N_{0}}=\frac{1}{1+\left(k_{1} N_{0}\right) \cdot t} . \\
& \frac{N_{1}}{N_{0}}=\frac{1}{\left(1+\frac{k_{1} N_{0}}{k_{2}}\right) \cdot\left(e^{k_{2} \cdot t}-1\right)+1} .
\end{aligned}
$$

The growth of nanoparticle in dry heat treatments is commonly described by the equation ${ }^{29}$ :

$$
D_{1}=D_{0}+k^{\prime} t^{\frac{1}{m}} \text {. }
$$

where $k^{\prime}$ is a constant, and $m$ is the grain growth exponent representing the grain growth behavior.

It is expected that the solid-state transformation behavior can be predicted using the kinetic models in which equations of the nucleation and growth are taken into consideration together. Accordingly, for the fraction of transformation, $\alpha$, from one phase to another phase in the phase transformation processes in dry heating treatments, with inserting $D_{1}$ from Eq. (7) and $N_{1} / N_{0}$ from Eq. (5) or (6) into Eq. (1), we propose the following kinetic models:

$$
\begin{aligned}
& \alpha=1-\frac{\left(1+k t^{1 / m}\right)^{3}}{1+\left(k_{1} N_{0}\right) t} . \quad \text { (Combining Eq. (1) } \\
& \text { with Eqs. (5) and (7)) } \\
& \alpha=1-\frac{\left(1+k t^{1 / m}\right)^{3}}{\left(1+\frac{k_{1} N_{0}}{k_{2}}\right) \cdot\left(e^{k_{2} \cdot t}-1\right)+1} . \\
& \text { (Combining Eq. (1) with Eqs. (6) and (7)) }
\end{aligned}
$$


In Eqs. (8) and (9), $k=k^{\prime} / D_{0}$ is an apparent kinetic constant relevant to the grain growth and $k_{1} N_{0}$ can be viewed as one complex constant.

Following the predictions of these models, phase transformation behavior of titania nanoparticles were evaluated by the published experimental data in the literature.

\section{Results and discussion}

\section{Phase transformation of nanocrystalline anatase to rutile at low temperature $\left(<600^{\circ} \mathrm{C}\right)$}

Fig. 2 shows the experimental data of formation of rutile in anatase $(\sim 6 \mathrm{~nm})$ samples in the temperature range of $465-525{ }^{\circ} \mathrm{C}^{12}$, alongside models curves (8) and (9). It may be observed that the experimental data at 465 and $480{ }^{\circ} \mathrm{C}$ can be satisfactorily predicted by the kinetic model (8) (Fig. 2 (a)). The deviation of kinetic model (8) [combining interface nucleation correlation (5) with the growth correlation (7)], over longer reaction times at temperatures of 500 and $525^{\circ} \mathrm{C}$, can be attributed to the presence of surface nucleation in the transformation process (an alternative interpretation other than that offered by Zhang and Banfield ${ }^{28}$ ); that the experimental data related to total reaction time at these two temperatures can be very satisfactorily fitted using the kinetic model (9) [combined interface and surface nucleation correlation (6) together with the growth correlation (7)] (Fig. 2 (b)). Parameters of kinetic models of (8) and (9) were obtained for various temperatures by the fitting of experimental data and the method of non-linear leastsquares fitting, as listed in Table 1.

Table 1 -Parameters for the kinetic models (8) and (9) with $m=1$, for transformation from anatase to rutile (Fig. 2)

\begin{tabular}{c|cc|c|c|c|c|c}
\hline \multirow{2}{*}{$T$} & \multicolumn{3}{|c|}{ Kinetic model (8) } & \multicolumn{5}{|c}{ Kinetic model (9) } \\
\cline { 2 - 8 }$\left({ }^{\circ} \mathrm{C}\right)$ & $\begin{array}{c}k_{1} N_{0} \\
\left(\mathrm{~h}^{-1}\right)\end{array}$ & $\begin{array}{c}k \\
\left(\mathrm{~nm} \mathrm{~h}^{-1}\right)\end{array}$ & $R^{2}$ & $\begin{array}{c}k_{1} N_{0} \\
\left(\mathrm{~h}^{-1}\right)\end{array}$ & $\begin{array}{c}k_{2} \\
\left(\mathrm{~h}^{-1}\right)\end{array}$ & $\begin{array}{c}k \\
\left(\mathrm{~nm} \mathrm{~h}^{-1}\right)\end{array}$ & $R^{2}$ \\
\hline 465 & 0.0049 & 0.00044 & 0.99 & - & - & - & - \\
480 & 0.0099 & 0.00089 & 0.987 & - & - & - & - \\
500 & 0.025 & 0.0021 & 0.992 & 0.034 & 0.0096 & 0.0064 & 0.9998 \\
525 & 0.069 & 0.0044 & 0.978 & 0.105 & 0.0346 & 0.0179 & 0.9986 \\
\hline
\end{tabular}

Zhang and Banfield, ${ }^{27,28}$ expressed that, at lower temperatures (less than $600{ }^{\circ} \mathrm{C}$ ), thermal fluctua-
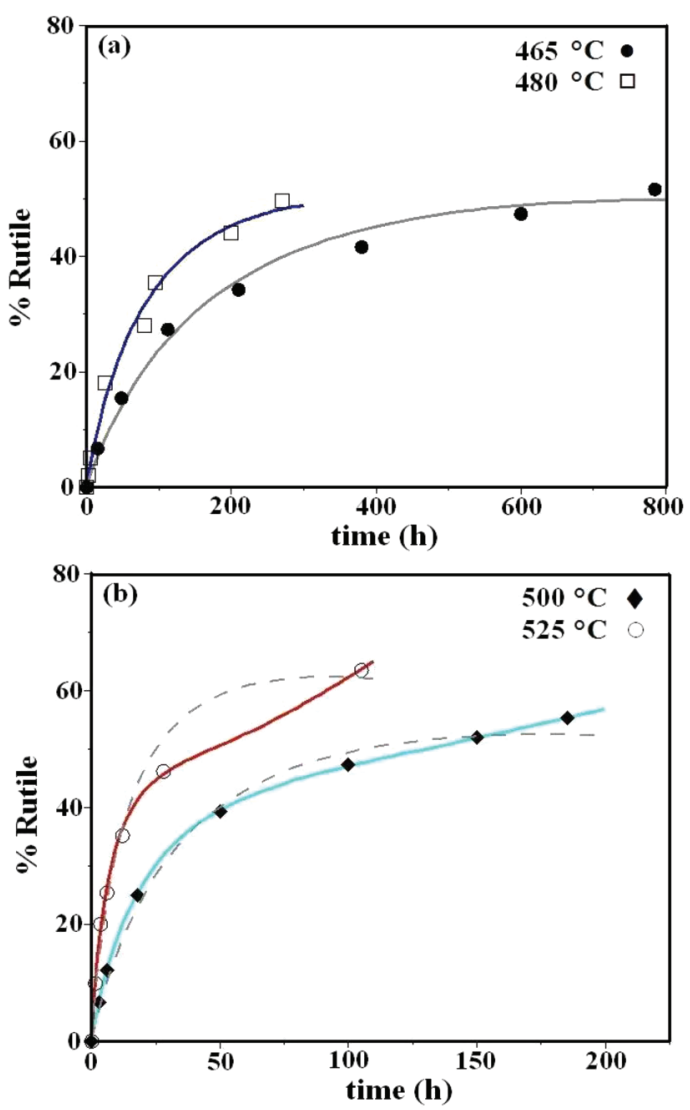

Fig. 2 - Points represent transformation experimental data from anatase to rutile ${ }^{12}$, and curves are fitted with (a) kinetic model (8), and (b) kinetic model (8) \{dashed lines\} and kinetic model (9) \{solid lines\}

tion of $\mathrm{Ti}$ and $\mathrm{O}$ atoms in anatase is not strong enough to generate rutile nuclei on the surfaces of the anatase; and only considered the dominant interface nucleation at phase transformation kinetics. However, according to the ratio of rate of surface nucleation to that of interface nucleation, as where Eq. (1) has been substituted, we have:

$$
\begin{aligned}
& \text { Ratio }=\frac{\text { rate }(\mathrm{SN})}{\operatorname{rate}(\mathrm{IN})}=\frac{k_{2} \cdot N_{1}}{k_{1} \cdot N_{1}^{2}}=\frac{k_{2}}{\left(k_{1} \cdot N_{0}\right) \cdot\left(\frac{N_{1}}{N_{0}}\right)}= \\
& =\frac{k_{2} \cdot\left(\frac{D_{1}}{D_{0}}\right)^{3}}{\left(k_{1} \cdot N_{0}\right) \cdot(1-\alpha)}=F(\text { temperature, time, particle size })
\end{aligned}
$$

It is seen that the presence and dominance of a mechanism of nucleation is dependent on various parameters, like temperature, time, particle size, and also particle packing ${ }^{30}$. In Fig. 2 (b), at experimental points, the approximation beginning of the deviation of curves of models (8) and (9), anatase sample characteristics according to Ref. ${ }^{12}$, are as follows: 


$$
\begin{aligned}
& \text { at } \quad T=500{ }^{\circ} \mathrm{C} \Rightarrow t_{\text {start deviation }} \approx 50 \mathrm{~h} \& D_{\text {anatase }} \approx 30 \mathrm{~nm} \& \alpha \approx 40 \% \\
& \text { at } \quad T=525{ }^{\circ} \mathrm{C} \Rightarrow t_{\text {start deviation }} \approx 15 \mathrm{~h} \& D_{\text {anatase }} \approx 30 \mathrm{~nm} \& \quad \alpha \approx 40 \%
\end{aligned}
$$

Using kinetic constants in Table 1, alongside the above data in Eq. (10), the ratio of the rate of surface nucleation to that of interface nucleation $(R)$, at 500 and $525{ }^{\circ} \mathrm{C}$, has been obtained to be greater than $1\left(R_{T}=500{ }^{\circ} \mathrm{C} \approx 17.4\right.$ and $R_{T}=525^{\circ} \mathrm{C} \approx$ 14.4). Therefore, expectedly, the surface nucleation and interface nucleation can play an important role at phase transformation in such conditions of heating for a long time at temperatures below $600{ }^{\circ} \mathrm{C}$.

With data of $k_{1} N_{0}$ in Table 1 at 465 and $480{ }^{\circ} \mathrm{C}$, activation energy of interface nucleation is obtained, $E_{a}(\mathrm{IN})=216 \mathrm{~kJ} \mathrm{~mol}^{-1}$ and also using data of $k_{1} N_{0}$ and $k_{2}$ listed in Table 1 for kinetic model (9), activation energies of interface nucleation and surface nucleation can be calculated: $E_{a}(\mathrm{IN})=231 \mathrm{~kJ} \mathrm{~mol}^{-1}$; $E_{a}(\mathrm{SN})=193 \mathrm{~kJ} \mathrm{~mol}^{-1}$.

A comparison of these $E_{a}$ data suggests that, with the presence and increase in participation of surface nucleation at phase transformation, activation energy for interface nucleation increases, which is perhaps indicative that with coarsening of anatase nanoparticles and reducing their contact surfaces, the rate of interface nucleation is reduced.

\section{Phase transformation of nanocrystalline anatase to rutile at high temperature $\left(>600^{\circ} \mathrm{C}\right)$}

Fig. 3 shows that the kinetic model (9) can also provide a good prediction of experimental data for the fraction of transformation of anatase $(\sim 8 \mathrm{~nm})$

Table 2 -Parameters for the kinetic model (9) with $m=3$, for transformation from anatase to rutile (Fig. 3)

\begin{tabular}{c|c|c|c|c}
\hline$T$ & $\begin{array}{c}k_{1} N_{0} \\
\left(\mathrm{~h}^{-1}\right)\end{array}$ & $\begin{array}{c}k_{2} \\
\left(\mathrm{~h}^{-1}\right)\end{array}$ & $\begin{array}{c}k \\
\left(\mathrm{~nm} \mathrm{~h}^{-0.33}\right)\end{array}$ & $R^{2}$ \\
\hline 620 & 0.17 & 0.0071 & 0.073 & 0.994 \\
640 & 0.48 & 0.050 & 0.20 & 0.994 \\
660 & 0.71 & 0.28 & 0.34 & 0.98 \\
680 & 0.99 & 0.51 & 0.32 & 0.998 \\
690 & 1.7 & 0.82 & 0.51 & 0.99 \\
\hline
\end{tabular}

Table 3 -Frequency factors, $A_{0}$, and activation energies, $E_{a^{\prime}}$ of Interface Nucleation and Surface Nucleation in phase transformation from anatase to rutile (at $T>600{ }^{\circ} \mathrm{C}$ )

\begin{tabular}{c|c|c|c}
\hline & $\begin{array}{c}E_{a} \\
\left(\mathrm{~kJ} \mathrm{~mol}^{-1}\right)\end{array}$ & $\begin{array}{c}A_{0} \\
\left(\mathrm{~h}^{-1}\right)\end{array}$ & $R^{2}$ \\
\hline$k_{1} N_{0}$ & $211[167]^{*}$ & $4.58 \cdot 10^{11}\left[3.8 \cdot 10^{11}\right]^{*}$ & 0.95 \\
$k_{2}$ & $478[466]^{*}$ & $9.24 \cdot 10^{24}\left[7.8 \cdot 10^{24}\right]^{*}$ & 0.96 \\
\hline
\end{tabular}

([] by Zhang and Banfield ${ }^{27}$ ) to rutile at temperatures ranging from 620 to $690{ }^{\circ} \mathrm{C}$. Model parameters were obtained for various temperatures by the fitting of experimental data and the method of non-linear least-squares fitting, as listed in Table 2. Arrhenius plot of the kinetic constants $k_{1} N_{0}$ and $k_{2}$ listed in Table 2 are shown in Fig. 4 , giving activation energies of interface nucleation and surface nucleation in phase transformation from anatase to rutile, respectively (Table 3 ).

Activation energy of surface nucleation obtained by the model presented by Zhang and Banfield $^{27}$ (listed in brackets in Table 3), in comparison with the value obtained with model (9), showed that, instead of using the experimental data of particle sizes of nanocrystalline anatase over the reaction times, a growth correlation is used and there is very little difference $(<3 \%)$. This result points out that, even when the experimental data of particle sizes at different times are not available, this model can be a good replacement instead of their model.
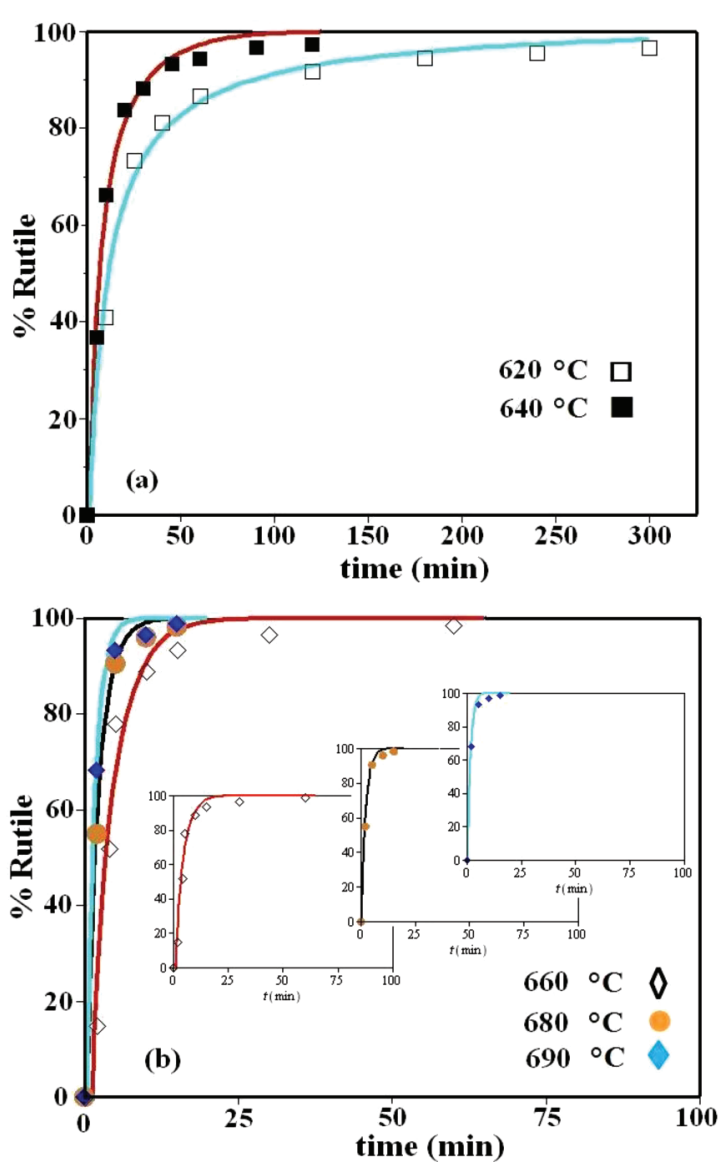

Fig. 3 - Points represent transformation experimental data from anatase to rutile ${ }^{27}$, and curves are fitted with Eq. (9) 
The greater difference in activation energy of interface nucleation ( $26 \%)$ may have been developed due to the use of only a series of experimental data (note the very large differences in values of kinetic constants for the interface nucleation, and their averages in Table 3 from Ref. ${ }^{27}$ )

Kinetic model (9) also provides a very satisfactory fit to the experimental data for the fraction of
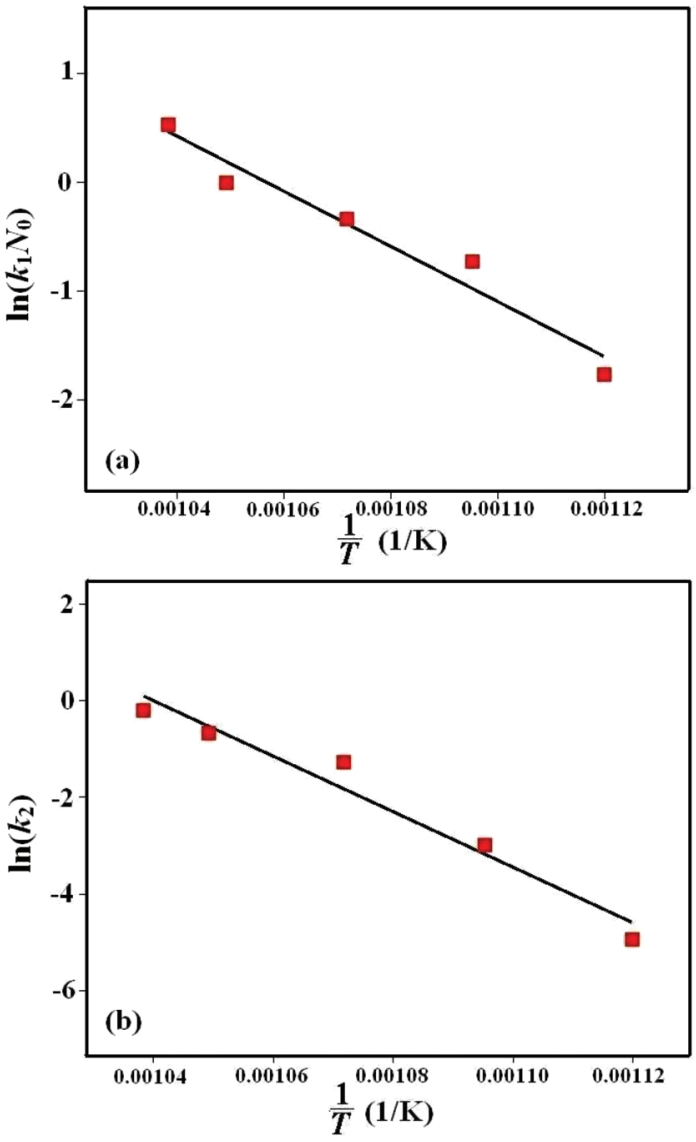

Fig. 4 -Arrhenius plot of the kinetic constants $k_{1} N_{0}$ and $k_{2}$ for transformation from anatase to rutile (at $T>600^{\circ} \mathrm{C}$ )

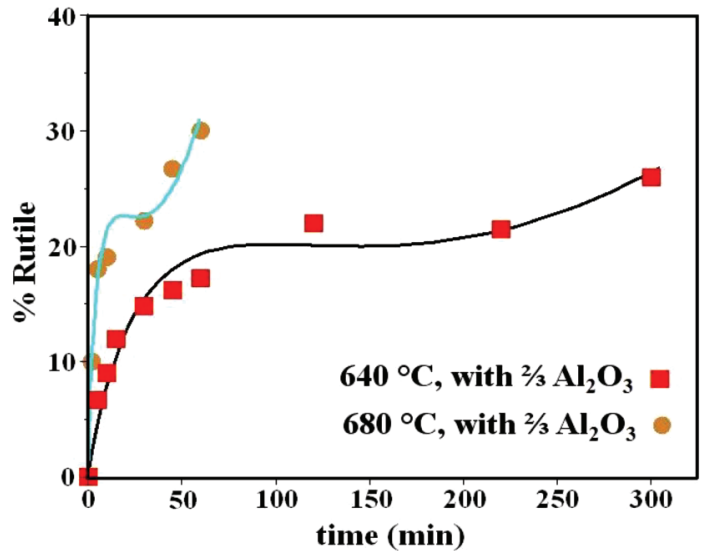

Fig. 5 - Points represent transformation experimental data from anatase to rutile ${ }^{27}$, and curves are fitted with Eq. (9) transformation of anatase to rutile in the presence of alumina nanoparticles (Fig. 5) at 640 and $680{ }^{\circ} \mathrm{C}$. Using nonlinear least-square fitting, the data points in Fig. 5 were fitted with Eq. (9), and the parameters $k_{1} N_{0}$ and $k_{2}$ were obtained (Table 4). With the data in Table 4, activation energies can be estimated: $E_{a}(\mathrm{IN})=321 \mathrm{~kJ} \mathrm{~mol}^{-1} ; E_{a}(\mathrm{SN})=308 \mathrm{~kJ} \mathrm{~mol}^{-1}$. It is observed that $E_{a}(\mathrm{SN})$ obtained from kinetic model (9), in comparison with $E_{a}(\mathrm{IN})$ is determined by the kinetic model employed by Zhang and Banfield $^{27}$, again, the difference is very small $(<1.5 \%)$.

Madras et al. ${ }^{31}$ have stated that their kinetic model based on population balance equation is not able to interpret the experimental results of phase transformation of anatase to rutile in the presence of alumina nanoparticles at $680{ }^{\circ} \mathrm{C}$, due to scattering data and their anomalous behavior; and also their model did not provide a good fit of the experimental data at $640{ }^{\circ} \mathrm{C}$.

\section{Conclusion}

In this research, we have developed kinetic models in which consideration of the nucleation and growth resulted in successful simulation of the experimental data for the phase transformation of nanocrystalline anatase to rutile at various temperatures. Compared with similar models for the interpretation of behavior of phase transformation from anatase to rutile at the nanoscale, which are related to experimental data of particle sizes of anatase during the kinetic experiments, these models can be a very good substitute, and are only dependent on the experimental data of fractions of transformation. The results also indicate that at low temperatures $\left(<600{ }^{\circ} \mathrm{C}\right)$, where, according to studies, the transformation occurs only by interface nucleation (IN), SN addition to IN can play an important role in the kinetics of phase transformation due to heating for a long period of time (e.g. $50 \mathrm{~h}$ at $500{ }^{\circ} \mathrm{C}$ ). We propose further evaluation of the predictability of kinetic models presented in this paper (Eqs. (8) and (9)) concerning the behavior of solid state phase transformations using different kinetic data for other polymorphs of materials, such as $\gamma-\mathrm{Al}_{2} \mathrm{O}_{3} \rightarrow \alpha-\mathrm{Al}_{2} \mathrm{O}_{3}$.

Table 4 -Parameters for the kinetic model (9) with $m=1$, for transformation from anatase to rutile in presence of alumina (Fig. 5)

\begin{tabular}{c|c|c|c|c}
\hline $\begin{array}{c}T \\
\left({ }^{\circ} \mathrm{C}\right)\end{array}$ & $\begin{array}{c}k_{1} N_{0} \\
\left(\mathrm{~h}^{-1}\right)\end{array}$ & $\begin{array}{c}k_{2} \\
\left(\mathrm{~h}^{-1}\right)\end{array}$ & $\begin{array}{c}k \\
\left(\mathrm{~nm} \mathrm{~h}^{-1}\right)\end{array}$ & $R^{2}$ \\
\hline 640 & 0.0203 & 0.00668 & 0.00569 & 0.968 \\
680 & 0.120 & 0.0366 & 0.0316 & 0.982 \\
\hline
\end{tabular}




\section{Nomenclature}

$$
\begin{array}{ll}
\alpha & - \text { fraction of transformation, }- \\
D^{*} & - \text { particle size, } \mathrm{nm} \\
N^{*} & - \text { number of particles, }- \\
\rho & - \text { density, } \mathrm{kg} \mathrm{m}^{-3} \\
t & - \text { time, } \mathrm{min}, \mathrm{h} \\
k_{1} & - \text { kinetic constants for the interface nucleation, } \mathrm{h}^{-1} \\
k_{2} & - \text { kinetic constants for the surface nucleation, } \mathrm{h}^{-1} \\
k, k^{\prime} & - \text { rate constant, } \mathrm{nm} \mathrm{h}^{-1} \\
m & - \text { grain growth exponent representing the grain } \\
& \quad \text { growth behavior, } \mathrm{nm} \mathrm{h}^{-0.33} \\
T & - \text { temperature, }{ }^{\circ} \mathrm{C}, \mathrm{K} \\
R^{2} & - \text { regression coefficient, }- \\
A_{0} & - \text { frequency factors, } \mathrm{h}^{-1} \\
E_{a} & - \text { activation energies, } \mathrm{kJ} \mathrm{mol}^{-1}
\end{array}
$$

*Index 0 and 1 indicate, respectively, quantities at the initial reaction time $(t=0)$ and their values at any time $t$

\section{References}

1. Banfield, J. F., Veblen, D. R., Conversion of perovskite to anatase and $\mathrm{TiO}_{2}$ (B): A TEM study and the use of fundamental building blocks for understanding relationships among the $\mathrm{TiO}_{2}$ minerals, American Mineralogist 77 (1992) 545 .

2. Yin, H., Wada, Y., Kitamura, T., Kambe, S., Murasawa, S., Mori, H., Sakata, T., Yanagida, S., Hydrothermal synthesis of nanosized anatase and rutile $\mathrm{TiO}_{2}$ using amorphous phase $\mathrm{TiO}_{2}$, J. Mater. Chem. 11 (2001) 1694. doi: https://doi.org//10.1039/b008974p

3. Gao, L., Zhang, Q., Effects of amorphous contents and particle size on the photocatalytic properties of $\mathrm{TiO}_{2}$ nanoparticles, Scripta Mater. 44 (2001) 1195. doi: https://doi.org//10.1016/S1359-6462(01)00681-9

4. Yin, S., Inoue, Y., Uchida, S., Fujishiro, Y., Sato, T., Crystallization of titania in liquid media and photochemical properties of crystallized titania, J. Mater. Res. 13 (1998) 844. doi: https://doi.org//10.1557/JMR.1998.0111

5. Ohtani, B., Ogawa, Y., Nishimoto, S., Photocatalytic activity of amorphous-anatase mixture of titanium(iv) oxide particles suspended in aqueous solutions, J. Phys. Chem. B 101 (1997) 3746. doi: https://doi.org//10.1021/jp962702+

6. Zou, J., Gao, J., Xie, F., An amorphous $\mathrm{TiO}_{2}$ sol sensitized with $\mathrm{H}_{2} \mathrm{O}_{2}$ with the enhancement of photocatalytic activity, J. of Alloys and compounds 497 (2010). 420. doi: https://doi.org//10.1016/j.jallcom.2010.03.093

7. Finnegan, M. P., Zhang, H., Banfield, J. F., Anatase coarsening kinetics under hydrothermal conditions as a function of $\mathrm{pH}$ and temperature, Chem. Mater. 20 (2008) 3443. doi: https://doi.org//10.1021/cm071057o

8. Madras, G., McCoy, B. J., kinetic model for transformation from nanosized amorphous $\mathrm{TiO}_{2}$ to anatase, Crystal Growth \& Design 7 (2007) 250. doi: https://doi.org//10.1021/cg060272z

9. Kumar, K. P., Growth of rutile crystallites during the initial stage of anatase-to-rutile transformation in pure titania and in titania-alumina nanocomposites, Scripta Metallurgica et Materialia 32 (1995) 873. doi: https://doi.org//10.1016/0956-716X(95)93217-R

10. Gennari, F. C., Pasquevich, D. M., Kinetics of the anatase-rutile transformation in $\mathrm{TiO}_{2}$ in the presence of $\mathrm{Fe}_{2} \mathrm{O}_{3}$, J. of Materials Science 33 (1998) 1571. doi: https://doi.org//10.1023/A:1017515804370

11. Shannon, R. D., Pask, J. A., Kinetics of the anatase-rutile transformation, J. of The American Ceramic Society 48 (1965) 391 doi: https://doi.org//10.1111/j.1151-2916.1965.tb14774.x

12. Gribb, A. A., Banfield, J. F., Particle size effects on transformation kinetics and phase stability in nanocrystalline $\mathrm{TiO}_{2}$, American Mineralogist 82 (1997) 717. doi: https://doi.org//10.2138/am-1997-7-809

13. Zhang, H., Banfield, J. F., Thermodynamic analysis of phase stability of nanocrystalline titania, J. Mater. Chem. 8 (1998) 2073. doi: https://doi.org//10.1039/a802619j

14. Zhang, H., Banfield, J. F., Understanding polymorphic phase transformation behavior during growth of nanocrystalline aggregates: Insights from $\mathrm{TiO}_{2}$, J. Phys. Chem. B 104 (2000) 3481 doi: https://doi.org//10.1021/jp000499j

15. Banfield, J. F., Bischoff, B. L., Anderson, M. A., TiO accessory minerals: coarsening, and transformation kinetics in pure and doped synthetic nanocrystalline materials, Chemical Geology 110 (1993) 211. doi: https://doi.org//10.1016/0009-2541(93)90255-H

16. Rao, C. N. R., Kinetics and thermodynamics of the crystal structure transformation of spectroscopically pure anatase to rutile, Can. J. Chem. 39 (1961) 498. doi: https://doi.org//10.1139/v61-059

17. Suzuki, A., Kotera, Y., The kinetics of the transition of titanium dioxide, Bulletin of the Chemical Society of Japan $\mathbf{3 5}$ (1962) 1353. doi: https://doi.org//10.1246/bcsj.35.1353

18. Czanderna, W., Rao, C. N. R., Honig, J. M., The anatase-rutile transition Part: I. Kinetics of the transformation of pure anatase, Transactions of the Faraday Society 54 (1958) 1069 . doi: https://doi.org//10.1039/TF9585401069

19. Heald, E. F., Weiss, C. W., Kinetics and mechanism of the anatase/rutile transformation, as catalyzed by ferric oxide and reducing conditions, American Mineralogist 57 (1972) 10.

20. MacKenzie, K. J. D., The calcination of titania V. Kinetics and mechanism of the anatase-rutile transformation in the presence of additives, Transactions and Journal of the British Ceramic Society 74 (1975) 77.

21. Suzuki, A., Tukuda, R., Kinetics of the transition of titanium dioxide prepared by sulfate process and chloride process, Bulletin of the Chemical Society of Japan 42 (1969) 1853. doi: https://doi.org//10.1246/bcsj.42.1853

22. Hishita, S., Mutoh, I., Koumoto, K., Yanagida, H., Inhibition mechanism of the anatase-rutile phase transformation by rare earth oxides, Ceramics International 9 (1983) 41. doi: https://doi.org//10.1016/0272-8842(83)90025-1

23. Kumar, K. N. P., Keizer, K., Burggraaf, A. J., Textural evolution and phase transformation in titania membranes: Part 1. Unsupported membranes, Journal of Materials Chemistry 3 (1993) 1141 doi: https://doi.org//10.1039/JM9930301141

24. Kumar, K. N. P., Keizer, K., Burggraaf, A. J., Okubo, T., Nagamoto, H., Textural evolution and phase transformation in titania membranes: Part 2. Supported membranes, J. Mat. Chern. 3 (1993) 1151. doi: https://doi.org//10.1039/JM9930301151 
25. Ragai, J., Lotfi, W., Effect of preparative $\mathrm{pH}$ and ageing media on the crystallographic transformation of amorphous $\mathrm{TiO}_{2}$ to anatase and rutile, Colloids and Surfaces 61 (1991) 97

doi: https://doi.org//10.1016/0166-6622(91)80302-5

26. Zhang, H., Banfield, J. F., Size dependence of the kinetic rate constant for phase transformation in $\mathrm{TiO}_{2}$ nanoparticles, Chem. Mater. 17 (2005) 3421 doi: https://doi.org//10.1021/cm0508423

27. Zhang, H., Banfield, J. F., Phase transformation of nanocrystalline anatase-to-rutile via combined interface and surface nucleation, J. Mater. Res. 15 (2000) 437. doi: https://doi.org//10.1557/JMR.2000.0067

28. Zhang, H., Banfield, J. F., New kinetic model for the nanocrystalline anatase-to-rutile transformation revealing rate dependence on number of particles, American Mineralogist 84 (1999) 528.

doi: https://doi.org//10.2138/am-1999-0406

29. $L u, K$., Nanocrystalline metals crystallized from amorphous solids: nanocrystallization, structure, and properties, Materials Science and Engineering 16 (1996) 161. doi: https://doi.org//10.1016/0927-796X(95)00187-5

30. Zhang, H., Banfield, J. F., Polymorphic transformations and particle coarsening in nanocrystalline titania ceramic powders and membranes, J. Phys. Chem. C 111 (2007) 6621. doi: https://doi.org//10.1021/jp067665t

31. Madras, G., McCoy, B. J., Navrotsky, A., Kinetic model for $\mathrm{TiO}_{2}$ polymorphic transformation from anatase to rutile, J. Am. Ceram. Soc. 90 (2007) 250. doi: https://doi.org//10.1111/j.1551-2916.2006.01369.x 